\title{
Volatile components and antimicrobial activity of the $n$-hexane extracts of Neomuretia pisidica (Kit Tan) Kljuykov, Degtjareva \& Zakharova
}

\author{
Ayşe Esra Karadağ ${ }^{1,2, *}$, (D) Betül Demirci ${ }^{3}$, (D) Ömer Çeçen ${ }^{4}$, (D) Ayvaz Ünal ${ }^{5}$ and (D) Fatma Tosun ${ }^{1}$
}

\begin{abstract}
${ }^{1}$ Department of Pharmacognosy, School of Pharmacy, Istanbul Medipol University, 34810, Istanbul, TURKEY
${ }^{2}$ Depatment of Pharmacognosy, Graduate School of Health Sciences, Anadolu University, Eskişehir, TURKEY

${ }^{3}$ Department of Pharmacognosy, Faculty of Pharmacy, Anadolu University, 26470, Eskişehir, TURKEY

${ }^{4}$ Department of Plant and Animal Production, Medical and Aromatic Plants Programme, Ermenek Vocational High School, Karamanoğlu Mehmetbey University, 70400, Ermenek, Karaman, TURKEY

${ }^{5}$ Department of Science Education, Faculty of Ahmet Keleşoğlu Education, Necmettin Erbakan University, 42090, Konya, TURKEY
\end{abstract}

*Corresponding author. Email: ayseesraguler@gmail.com

Submitted: 13.11.2020; Accepted: 06.01.2021

\begin{abstract}
The fruits, aerial parts and roots of Neomuretia pisidica (Kit Tan) Kljuykov, Degtjareva \& Zakharova were extracted with $n$-hexane. Total of 18 compounds were characterised by GC analyses of the $n$-hexane extracts. Main volatile components of the $n$-hexane extract of aerial parts were characterized as 1,8-cineole (23.4\%), camphor (21.4\%), 2-ethyl hexanol (14.6\%), $\alpha$-pinene (7.2\%), and verbenone (6.4\%). Methyl linoleate (19.3\%), 1,8-cineole (16.5\%), camphor (13.2\%), $\alpha$-pinene (6.1\%) and 2-ethyl hexanol (4.9\%) were found in the $n$-hexane extract of roots. Whereas, 1,8-cineole (23.3\%), camphor (20.3\%), 2-ethyl hexanol (14.2\%), $\alpha$-pinene (9.9\%), and limonene (4.1\%) were the major components of the $n$-hexane extract of fruits. Antimicrobial activity were identified using a microdilution assay against selected human pathogenic strains. The most potent inhibitor activities with $156 \mu \mathrm{g} / \mathrm{mL}$ concentrations were detected against $S$. aureus and $E$. faecalis.
\end{abstract}

Keywords: Neomuretia pisidica, Apiaceae, volatile compounds, antimicrobial activity

\section{Introduction}

Neomuretia (Apiaceae) is a new genus of geophytic plants that represented by two species distributed in the Mediterranean region of Turkey and Northern Iraq. Neomuretia pisidica (Kit Tan) Kljuykov, Degtjareva \& Zakharova (syn. Hellenocarum pisidicum) is an endemic species growing in the Karaman province of Turkey (Zakharova et al., 2016). Apiaceae species are among the richest in essential oils (Baser\&Kirimer, 2014; Oroojelian et al., 2010; Sarebkhar\&Iranshahi, 2010; Tabanca et al., 2006). Akalın et al., 2009 and Kljuykov et al., 2020 published recent botanical reviews on the family. According to our interviews with local people, basal leaves of this species are used as food and for the treatment of toothaches.

The current study was aimed to investigate the volatile components and antimicrobial activity of the $n$ hexane extracts of $N$. pisidica.

\section{Materials and Methods}

\section{Plant material}

The roots, aerial parts, and fruits of N. pisidica were collected from the northern slopes of Göksu river valley near Akçaalan village, Karaman Province in 2017, and identified by one of us (ÖÇ). Voucher specimens were deposited at the GAZI Herbarium (Herbarium No: 2986). 


\section{Extraction of plant materials}

The air-dried plant materials (fruit, root, and aerial parts; each $200 \mathrm{~g}$ ) were separately powdered and extracted with $n$-hexane $(3 \times 200 \mathrm{~mL})$ at room temperature and filtered. The $n$-hexane was removed in a rotary evaporator in vacuo.

\section{GC-MS analysis}

The GC-MS analysis was carried out using an Agilent 5975 GC-MSD system. The analysis conditions were as described in our previous publication (Karaca et.al., 2020).

\section{GC analysis}

The analyzes were carried out as described in previous publications (Karaca et.al., 2020). GC analysis results are given in Table 1. Computer matching against commercial (Wiley GC/MS Library, MassFinder Software 4.0) $(1,2)$ and in-house "Başer Library of Essential Oil Constituents" built up by genuine compounds and components of known oils.

\section{Antibacterial activity}

The antibacterial activity was studied using broth microdilution assay following the methods described by the CLSI, Clinical and Laboratory Standards Institute Standards (CLSI, 2006). The potential minimum inhibitory concentrations (MIC) were calculated against the selected human pathogenic; Pseudomonas aeruginosa ATCC 10145, Enterococcus faecalis ATCC 29212, Staphylococcus aureus ATCC 6538, and Escherichia coli NRLL B-3008. The activity was studied as described in previous publications (Karadağ et.al., 2019). The antibacterial evaluations were in triplicates and reported as mean in Table 2.

\section{Results and Discussion}

The volatile constituents of the $n$-hexane extracts of $N$. pisidica fruits, roots, and aerial parts were analyzed using GC-FID and GC-MS which led to the identification of eighteen compounds. The main components of the $n$-hexane extract of the aerial parts were characterized as 1,8-cineole (23.4\%), camphor (21.4\%), 2-ethyl hexanol (14.6\%), $\alpha$-pinene (7.2\%), and verbenone (6.4\%). Methyl linoleate (19.3\%), 1,8-cineole (16.5\%), camphor (13.2\%), $\alpha$-pinene $(6.1 \%)$ and 2-ethyl hexanol $(4.9 \%)$ were identified in the $n$-hexane extract of roots. Whereas, 1,8-cineole (23.3\%), camphor (20.3\%), 2-ethyl hexanol (14.2\%), $\alpha$-pinene (9.9\%), and limonene (4.1\%) were the major components of the $n$-hexane extract of fruits.

Table 1.The Volatile Composition of Neomuretia pisidica $n$-hexane extracts

\begin{tabular}{llccc}
\hline RRI & Compounds & Aerial part \% & Fruit \% & Root \% \\
\hline 1032 & a-Pinene & 7.2 & 9.9 & 6.1 \\
1076 & Camphene & 1.8 & 3.2 & 1.6 \\
1093 & Hexanal & - & 1.3 & - \\
1174 & Myrcene & 1.5 & 2.5 & 1.0 \\
1194 & Heptanal & - & 1.3 & - \\
1203 & Limonene & 3.1 & 4.1 & 2.3 \\
1213 & 1,8-Cineole & 23.4 & 23.3 & 16.5 \\
1280 & p-Cymene & 4.5 & 2.7 & 1.5 \\
1496 & 2-Ethyl hexanol & 14.6 & 14.2 & 4.9 \\
1532 & Camphor & 21.4 & 20.3 & 13.2 \\
\hline
\end{tabular}




\begin{tabular}{lllcc}
\hline 1536 & Pinocamphone & 3.2 & 3.0 & 1.6 \\
1553 & Linalool & 3.5 & 2.5 & 1.1 \\
1706 & Q-Terpineol & 1.3 & 0.8 & 0.5 \\
1719 & Borneol & 5.0 & 2.8 & 2.2 \\
1725 & Verbenone & 6.4 & 3.8 & 2.8 \\
2242 & Methyl hexadecanoate & - & - & 4.3 \\
2509 & Methyl linoleate & - & - & 19.3 \\
2583 & Methyl linolenate & - & - & 4.1 \\
\hline & Total & $\mathbf{9 6 . 9}$ & $\mathbf{9 5 . 7}$ & $\mathbf{8 3 . 0}$
\end{tabular}

RRI: Relative retention indices calculated against $n$-alkanes. \%: Calculated from FID data

Table 2. Antimicrobial activities of the $n$-hexane extracts of $N$. pisidica (MICs in $\mathrm{mg} / \mathrm{mL}$ )

\begin{tabular}{lcccc}
\hline Sample & P. aeruginosa & S. aureus & E. coli & E. faecalis \\
\hline Fruit extract & 2.5 & 2.5 & 0.625 & 0.156 \\
Root extract & 2.5 & 0.156 & 0.625 & 0.156 \\
Aerial part extract & 1.25 & 0.156 & 1.25 & 0.312 \\
Tetracycline & 16 & 0.25 & $>16$ & 0.025 \\
\hline
\end{tabular}

Antimicrobial activities of the $n$-hexane extracts of $N$. pisidica against bacterial strains were listed, in Table 2 . The results revealed that the tested extracts are effective on S. aureus and E. faecalis at between 312-156 $\mu \mathrm{g} / \mathrm{mL}$ concentration. In previous studies, the antimicrobial activities of 1,8-cineole (Hendry et al., 2009; Kifer et al., 2016; Vuuren et al., 2007) and camphor (Jirovetz et al., 2005) are studied and demonstrated that camphor and 1,8-cineole have remarkable antimicrobial capacity. Based on this, it can be thought that the antimicrobial effect of $N$. pisidica essential oils is caused by camphor and 1,8-cineole. Furthermore, the antinociceptive and antiinflammatory activities of 1,8-cineole, camphor and essential oils that contain large proportional amounts of 1,8-cineole and camphor were proven (Lenardão et al., 2016; Chandrakanthan et al., 2020; Santos et al., 2000; Barkin, 2013). Thus, antinociceptive and antiinflammatory activities may explain the folkloric usage of $N$. piscidica for toothache.

Essential oils are known for their antimicrobial effects, and the different volatile components they contain may be responsible for this effect. In studies conducted with $n$-hexane extracts rich in volatile components, it has the potential of antibacterial effect as much as essential oils.

\section{CONFLICTS OF INTEREST}

The authors have no conflicts of interest to declare.

\section{REFERENCES}

Akalın, E., Özhatay, N., Özhatay, E., \& Ünlü, S. (2009). Rare and endemic taxa of Apiaceae in Turkey and their conservation significance. İstanbul Üniversitesi Eczacılık Fakültesi Dergisi, 40, 1-10.

Barkin, R. L. (2013). The pharmacology of topical analgesics. Postgraduate Medicine, 125(sup1), 7-18.

Baser, K. H. C., \& Kirimer, N. (2014). Essential oils of Anatolian Apiaceae-A profile. Natural Volatiles and Essential Oils, 1(1), 1-50. 
Chandrakanthan, M., Handunnetti, S. M., Premakumara, G. S. A. and Kathirgamanathar, S. (2020). Topical antiInflammatory activity of essential oils of Alpinia calcarata Rosc., its main constituents, and possible mechanism of action. Evidence-Based Complementary and Alternative Medicine, 2020, 2035671.

Clinical and Laboratory Standards Institute M7-A7, 2006. Methods for Dilution Antimicrobial Susceptibility Tests for Bacteria That Grow Aerobically; Approved Standard-Seventh Edition, CLSI document A. Wayne, Pa. USA. 26(2).

Hendry, E. R., Worthington, T., Conway, B. R., \& Lambert, P. A. (2009). Antimicrobial efficacy of eucalyptus oil and 1, 8cineole alone and in combination with chlorhexidine digluconate against microorganisms grown in planktonic and biofilm cultures. Journal of Antimicrobial Chemotherapy, 64(6), 1219-1225.

Jirovetz, L., Buchbauer, G., Denkova, Z., Stoyanova, A., Murgov, I., Schmidt, E., \& Geissler, M. (2005). Antimicrobial testinas and gas chromatoaraphic analysis of pure oxyaenated monoterpenes 1.8 -cineole, $\alpha$-terpineol, terpinen-4-ol and camphor as well as target comoounds in essential oils of pine (Pinus pinaster), rosemary (Rosmarinus officinalis), tea tree (Melaleuca alternifolia). Scientia Pharmaceutica, 73(1), 27-39.

Karaca, N., Şener, G., Demirci, B., \& Demirci, F. (2020). Synergistic antibacterial combination of Lavandula latifolia Medik. essential oil with camphor. Zeitschrift für Naturforschung C, 1(ahead-of-print).

Karadağ, A. E., Demirci, B., Çaşkurlu, A., Demirci, F., Okur, M. E., Orak, D., Başer, K. H. C. (2019). In vitro antibacterial, antioxidant, anti-inflammatory and analgesic evaluation of Rosmarinus officinalis L. flower extract fractions. South African Journal of Botany, 125, 214-220.

Kifer, D., Mužinić, V., \& Klarić, M. Š. (2016). Antimicrobial potency of single and combined mupirocin and monoterpenes, thymol, menthol and 1, 8-cineole against Staphylococcus aureus planktonic and biofilm growth. The Journal of Antibiotics, 69(9), 689-696.

Kljuykov, E. V., Petrova, S. E., Degtjareva, G. V., Zakharova, E. A., Samigullin, T. H., \& Tilney, P. M. (2020). A taxonomic survey of monocotylar Apiaceae and the implications of their morphological diversity for their systematics and evolution. Botanical Journal of the Linnean Society, 192(3), 449-473.

Lenardão, E. J. Savegnago, L., Jacob, R. G., Victoria, F. N. and Martinez, D. M. (2016). Antinociceptive effect of essential oils and their constituents: an update review. Journal of the Brazilian Chemical Society, 27(3), 435-474.

Oroojalian, F., Kasra-Kermanshahi, R., Azizi, M., \& Bassami, M. R. (2010). Phytochemical composition of the essential oils from three Apiaceae species and their antibacterial effects on food-borne pathogens. Food chemistry, 120(3), 765770.

Santos, F.A. and Rao, V.S.N. (2000). Antiinflammatory and antinociceptive effects of 1,8-Cineole a terpenoid oxide present in many plant essential oils. Phytotherapy Research, 14, 240-244.

Sahebkar, A., \& Iranshahi, M. (2010). Biological activities of essential oils from the genus Ferula (Apiaceae). Asian Biomedicine, 4(6), 835-847.

Tabanca, N., Demirci, B., Ozek, T., Kirimer, N., Baser, K. H. C., Bedir, E., Wedge, D. E. (2006). Gas chromatographic-mass spectrometric analysis of essential oils from Pimpinella species gathered from Central and Northern Turkey. Journal of Chromatography A, 1117(2), 194-205.

Vuuren, S. V., \& Viljoen, A. M. (2007). Antimicrobial activity of limonene enantiomers and 1, 8-cineole alone and in combination. Flavour and Fragrance Journal, 22(6), 540-544.

Zakharova, E.A., Kljuykov, E.V., Degtjareva, G.V., Samigullin, T., Ukrainskaya, U.A., \& Downie, S.R. (2016). A taxonomic study of the genus Hellenocarum $\mathrm{H}$. Wolff (Umbelliferae-Apioideae) based on morphology, fruit anatomy, and molecular data. Turkish Journal of Botany, 40(2), 176-193. 